\title{
Numerical Studies of Supersonic Planar Mixing and Turbulent Combustion using a Detached Eddy Simulation (DES) Model
}

\author{
Krithika Vyasaprasath* \\ Pusan National University, Busan 46241, Republic of Korea \\ Sejong Oh**, Kui-Soon Kim** and Jeong-Yeol Choi*** \\ Pusan National University, Busan 46241, Republic of Korea
}

\begin{abstract}
We present a simulation of a hybrid Reynolds-averaged Navier Stokes / Large Eddy Simulation (RANS/LES) based on detached eddy simulation (DES) for a Burrows and Kurkov supersonic planar mixing experiment. The preliminary simulation results are checked in order to validate the numerical computing capability of the current code. Mesh refinement studies are performed to identify the minimum grid size required to accurately capture the flow physics. A detailed investigation of the turbulence/chemistry interaction is carried out for a nine species 19-step hydrogen-air reaction mechanism. In contrast to the instantaneous value, the simulated time-averaged result inside the reactive shear layer underpredicts the maximum rise in $\mathrm{H}_{2} \mathrm{O}$ concentration and total temperature relative to the experimental data. The reason for the discrepancy is described in detail. Combustion parameters such as $\mathrm{OH}$ mass fraction, flame index, scalar dissipation rate, and mixture fraction are analyzed in order to study the flame structure.
\end{abstract}

Key words: Hybrid LES/RANS, supersonic combustion, turbulence/chemistry interaction, planar mixing, flame structure.

\section{Introduction}

The supersonic combustion process in high speed vehicles accompanied by the interaction of turbulence and finite rate chemistry is a complex phenomenon. The use of computational fluid dynamics (CFD) to model turbulent combustion and consistently yield the right answer can be very tricky. The modeling of such high-speed reactive flows is extremely helpful in understanding the physical processes occurring inside scramjet engines. However, the results of computational simulations used to predict actual flight test conditions still remains questionable and continuously requires improvement. The validation of a numerical model against a realistic engine test is necessary to build confidence in the numerical modeling approach. The planar mixing supersonic combustion experiment by Burrows and Kurkov has been used extensively to verify and validate a number of numerical codes in recent years.

Previously, studies by Evans et al. on "unmixedness" (richness in fuel or oxygen) replaced the eddy breakup model with finite rate chemistry that corrected for the unmixedness term. Their study suggests that unmixedness may lead to serious errors in time-averaged temperature and composition profiles $[1,2]$. Subsequently, other combustion models such as the Favre-averaged Navier Stokes (FANS), Reynoldsaveraged Navier Stokes (RANS), and sophisticated probability density function (PDF) models have been validated for the benchmark case of Burrows-Kurkov [3-5]. These studies demonstrate both the numerical capability and limitations in capturing the real flow physics. Many studies have shown the importance of optimizing the turbulent Prandtl number and Schmidt number [5-7], and the impact of turbulencechemistry interactions in reactive turbulent flows [8-10]. Although the RANS model has been used extensively to solve
This is an Open Access article distributed under the terms of the Creative Commons Attribution Non-Commercial License (http://creativecommons.org/licenses/by$\mathrm{nc} / 3.0 /$ which permits unrestricted non-commercial use, distribution, and reproduction in any medium, provided the original work is properly cited.

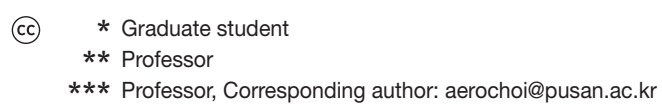


various problems, the unsteady dissipative nature of the turbulent combustion flow feature requires a time-accurate method such as large eddy simulation (LES) to capture the real turbulent flow features.

In order to overcome the limitations possessed by RANS or hybrid RANS/LES, attempts have been made to resolve large scale eddies while the small scale eddies, which are less energetic in their transportation of mass, momentum, and energy, are modeled but not resolved. A numerical simulation of a coaxial jet experiment [11] has been used to compare a RANS simulation with RANS/LES, and identifies deficiencies in the RANS model. The major disadvantage in RANS/LES is the control of the excess dissipation, and the necessity for blending of RANS and LES equations. A strategy to blend the RANS and LES equations is proposed by Spalart et al. [12] in which the LES equations are used for a flow regime that is separated from the walls, whereas the RANS technique is used for wall computations. Many studies [13-16] have concentrated on building numerical strategies for hybrid RANS/LES techniques in attempts to capture the coupling effect of turbulence and chemistry in order to predict the characteristics of high speed combustion. Recently, Edwards et al. simulated the well-known Burrows and Kurkov test case by implementing an improved version of the hybrid RANS/LES strategy, and produced good agreement with the experimental data [17].

Another feasible hybrid technology used in turbulent reacting flows is detached eddy simulation (DES), which is a less expensive strategy than LES. Peterson and Candler used DES methodology in the supersonic-combustion scramjet (SCHOLAR) experiment [18, 19], demonstrating agreement with the wall pressure distributions and experimental CARS images. The unsteady nature of turbulence was well captured by DES in a scramjet combustor configuration for transverse fuel injection with a cavity flame holder, as described in [20, 21]. Recently, Choi et al. studied the dependency of numerical predictions on the resolution of the flow field by comparing higher order approaches such as the monotone upstreamcentered schemes for conservation laws (MUSCL), the weighted essentially non-oscillating (WENO) scheme, and the optimized multidimensional limiting process (oMLP) scheme $[22,23]$. They showed the remarkable capability of oMLP in predicting turbulent flame structure, but had problems due to the axisymmetric geometry.

In this study, we performed a two-dimensional (2-D) simulation of a supersonic planar injection mixing case from the Burrows and Kurkov experiment, wherein a turbulent reactive shear layer is formed by molecular-level mixing near the splitter plate. The computational code uses DES strategy with high resolution numerical schemes for capturing the reactive turbulent flow field, and the ability to capture the turbulent combustion flow physics was tested.

\section{Numerical Approach}

\subsection{Governing Equation}

The traditional approach to modeling turbulent reactive flows is to solve mass, momentum, energy and species conservation equations through a RANS equation. The conservative vector form for $\mathrm{N}$ number of species in $(\xi, \eta)$ coordinates is given by

$$
\frac{\partial Q}{\partial t}+\frac{\partial E}{\partial x}+\frac{\partial F}{\partial y}+\frac{1}{y} H=\frac{\partial E_{v}}{\partial x}+\frac{\partial F_{v}}{\partial y}+\frac{1}{y} H_{v}+W
$$

where

$$
\begin{gathered}
Q=\left[\begin{array}{c}
\rho_{k} \\
\rho u \\
\rho v \\
\rho e \\
\rho k \\
\rho \omega
\end{array}\right], E=\left[\begin{array}{c}
\rho_{k} u \\
\rho u^{2}+p \\
\rho u v \\
(e+p) u \\
\rho u k \\
\rho u \omega
\end{array}\right], F=\left[\begin{array}{c}
\rho_{k} v \\
\rho v u \\
\rho v^{2}+p \\
(e+p) v \\
\rho v k \\
\rho v \omega
\end{array}\right], H=\left[\begin{array}{c}
\rho_{k} v \\
\rho v u \\
\rho v^{2} \\
(e+p) v \\
\rho v k \\
\rho v \omega
\end{array}\right] \\
E_{v}=\left[\begin{array}{c}
-\rho_{k} u_{k}^{d} \\
\tau_{x x} \\
\tau_{x y} \\
\beta_{x} \\
\mu_{\mathrm{k}} \frac{\partial k}{\partial x} \\
\mu_{\omega} \frac{\partial \omega}{\partial x}
\end{array}\right], F_{v}=\left[\begin{array}{c}
-\rho_{k} v_{k}^{d} \\
\tau_{y x} \\
\tau_{y y} \\
\beta_{y} \\
\mu_{\mathrm{k}} \frac{\partial k}{\partial y} \\
\mu_{\omega} \frac{\partial \omega}{\partial y}
\end{array}\right], H_{v}=\left[\begin{array}{c}
-\rho_{k} u_{k}^{d} \\
\tau_{y x} \\
\tau_{y y}-\tau_{\theta \theta} \\
\beta_{y} \\
\mu_{\mathrm{k}} \frac{\partial k}{\partial y} \\
\mu_{\omega} \frac{\partial \omega}{\partial y}
\end{array}\right], W=\left[\begin{array}{c}
\omega_{k} \\
0 \\
0 \\
0 \\
s_{k} \\
s_{\omega}
\end{array}\right]
\end{gathered}
$$

Spatial discretization is resolved through the finite volume approach. A fourth-order central difference scheme was used to formulate viscous fluxes. A detailed description of the numerical formulation is given in [26]. The artificial dissipation of numerical fluxes was formulated by using the improved version of Advection Upstream Splitting Method based on pressure (AUSMPW+) flux splitting method along with higher-order schemes such as oMLP, WENO, and MUSCL.

The present simulation was computed using the oMLP scheme with the AUSMPW+ flux splitting method. Previous studies $[22,23]$ demonstrated excellent numerical performance for turbulent combustion prediction.

\subsection{Thermochemical Model}

We implemented the conventional Jachimowski 19-step hydrogen-air reaction model with eight reacting species $(\mathrm{H}$, $\mathrm{H}_{2}, \mathrm{O}, \mathrm{O}_{2}, \mathrm{H}_{2} \mathrm{O}, \mathrm{OH}, \mathrm{HO}_{2}$, and $\mathrm{H}_{2} \mathrm{O}_{2}$ ) and one inert species 
$\left(\mathrm{N}_{2}\right)$. Thermodynamic properties such as enthalpies and specific heats were taken from McBride et al. [25]. The mean molecular weight and characteristic temperatures for each species were taken from Gas Research Institute (GRI Mech 3). The mixture viscosity and thermal conductivity was computed using Wilke's law. The Prandtl and Schmidt numbers were set to 0.9 and 0.4 . The diffusion coefficient calculation is based on Chapmann-Enskog theory. The production or depletion of the chemical species was formulated using the law of mass action and the NavierStokes equation.

\subsection{Turbulence Model}

Turbulence was modeled by using the standard k- $\omega$ shear stress transport (SST) model for high Reynolds numbers. The SST formulation shifts from a k- $\omega$ characteristic in the free-stream to $\mathrm{k}-\omega$ in the inner parts of the boundary layer, thereby making the model more suitable for solving the viscous sub-layer. The free stream turbulence recommended values are $\omega_{\infty}=(1 \sim 10) \frac{u_{\infty}}{L}, \mu_{T \infty}=10^{-(2 \sim 5)} \mu_{L \infty}$ and $k_{\infty}=$ $\frac{\mu_{T \infty}}{\rho_{\infty}} \omega_{\infty}$ where the fluid dynamic length scale (L) is equal to the length of the computational domain. Turbulent flows with high Reynolds numbers form large scale eddies that are well captured by using the DES approach. Spalart et al. [12] formulated the DES methodology, implementing both RANS and LES strategies. However, in this approach, only one fourth of the turbulence scale is resolved and the rest are modeled. A turbulent subgrid-scale model was not used in this study.

\section{Experimental Setup and Initial Conditions}

The geometry of the experimental setup is shown in Fig. 1. Hydrogen is injected through a slot in a step on the lower wall of the combustor duct at a sonic speed. A splitter plate with a thickness of $0.4 \mathrm{~cm}$ separates the air and the fuel flow within a combustor zone of length $35.6 \mathrm{~cm}$. This test includes surveys of the mole fraction, pitot pressure, and stagnation temperature measurements for both inert and reacting conditions. The major limitation of the Burrows-Kurkov database [27] is insufficient data related to the boundary layer growth rate of the combustor side walls, since the pitot probe size $(0.81 \mathrm{~mm})$ is too large to measure the true boundary layer profile. To develop a boundary layer thickness of about $1 \mathrm{~cm}$, a $51 \mathrm{~cm}$-long flat plate was simulated for the initial boundary layer profiles. The initial conditions for this case are described in Table 1.

\section{Computational Grid and Boundary Condi- tions}

Figure 2 shows the computational domain with three zones: a combustor zone, an air zone, and a fuel zone. The first smallest mesh, used for the 2-D calculation, contains a grid size of $181 \times 131$ (main combustor) +251 $\times 101$ (air zone) $+31 \times 26$ (fuel zone). The rest of the grid size information is given in Table 2. Figure 3 shows the configuration of the computational domain for a grid size of $721 \times 521$. The mesh is clustered at the side walls, which accounts for the formation of the boundary layer. Most of the grid is concentrated from the splitter plate extending to the combustor exit. The mesh is well clustered near the

Table 1. Inflow conditions for Burrows and Kurkov experiment

\begin{tabular}{lll}
\hline Property & $\begin{array}{l}\text { Hydrogen } \\
\text { Jet }\end{array}$ & $\begin{array}{l}\text { Vitiated } \\
\text { Air }\end{array}$ \\
\hline Mach Number & 1.0 & 2.44 \\
Temperature (K) & 254 & 1270 \\
Pressure (Mpa) & 0.1 & 0.1 \\
Velocity (m/s) & 1216 & 1764 \\
$\mathrm{Y}_{\mathrm{H} 2}$ & 1.0 & 0.0 \\
$\mathrm{Y}_{\mathrm{O} 2}$ & 0.0 & 0.258 \\
$\mathrm{Y}_{\mathrm{H} 2 \mathrm{O}}$ & 0.0 & 0.256 \\
$\mathrm{Y}_{\mathrm{N} 2}$ & 0.0 & 0.486 \\
\hline
\end{tabular}

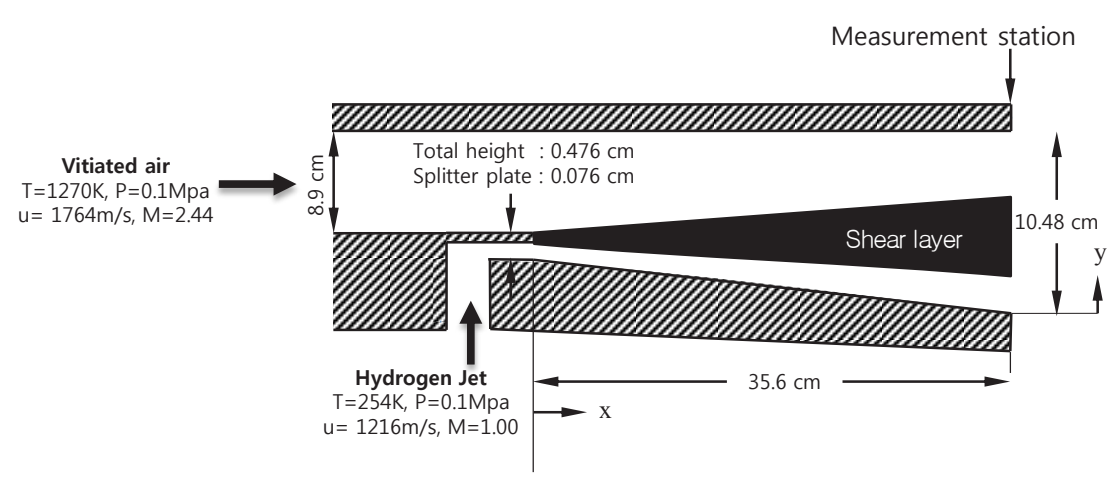

Fig. 1. Schematic of Burrows and Kurkov experiment 
splitter plate and extended in the axial direction in order to capture the formation of the shear layer, where mixing is followed by combustion. Very few meshes were used in the free stream region because there is no significant change in the flow phenomena except for the boundary layer, thereby reducing the computational time. The air zone extended over the negative span of $51 \mathrm{~cm}$ was used to produce the incoming initial boundary layer because of the absence

Table 2. Computational grid size information

\begin{tabular}{llll}
\hline & $\begin{array}{l}\text { Mixing } \\
\text { Zone }\end{array}$ & $\begin{array}{l}\text { Oxidizer } \\
\text { Zone }\end{array}$ & Fuel Zone \\
\hline Case 1 & $181 \times 131$ & $251 \times 101$ & $31 \times 26$ \\
Case 2 & $361 \times 261$ & $501 \times 201$ & $61 \times 51$ \\
Case 3 & $541 \times 391$ & $751 \times 301$ & $91 \times 76$ \\
Case 4 & $721 \times 521$ & $201 \times 401$ & $61 \times 101$ \\
Case 5 & $1001 \times 521$ & $101 \times 401$ & $61 \times 101$ \\
\hline
\end{tabular}

of wind tunnel geometry. An adiabatic wall temperature was imposed on all wall boundaries, with a no-slip wall boundary condition accounting for the formation of the boundary layer.

The Courant Friedrichs Lewy (CFL) number was set to 1 for the course grid and 3 for the fine grid sizes. A maximum of four sub-iterations were allowed at each time step. The time-averaged calculation was performed after the initial transient period of 10,000 time steps.

\section{Results and Discussion}

Generally, for turbulent flow, the time-averaged calculations are performed only after fluctuations in the solution are uniform. In order to check the steadiness of the solution, the static pressure with respect to the physical

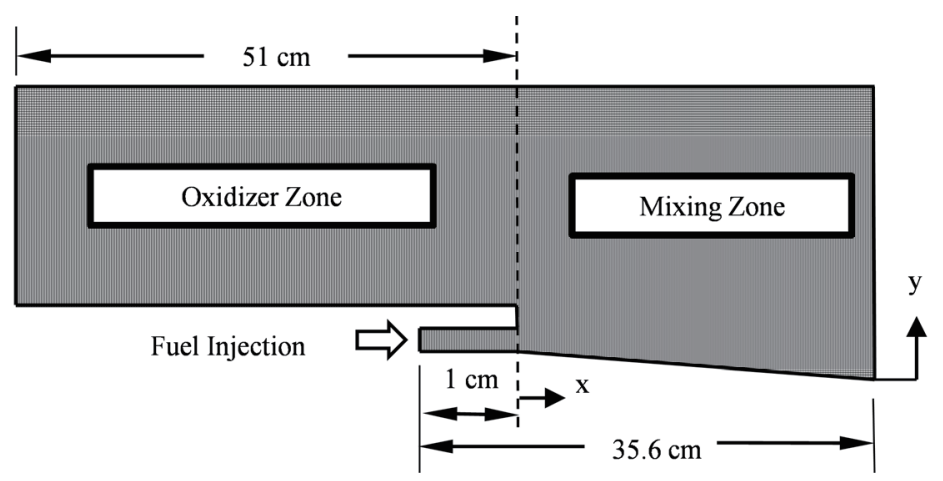

Fig. 2. Computational domain with the dimensions of the wind tunnel (For boundary layer formation).
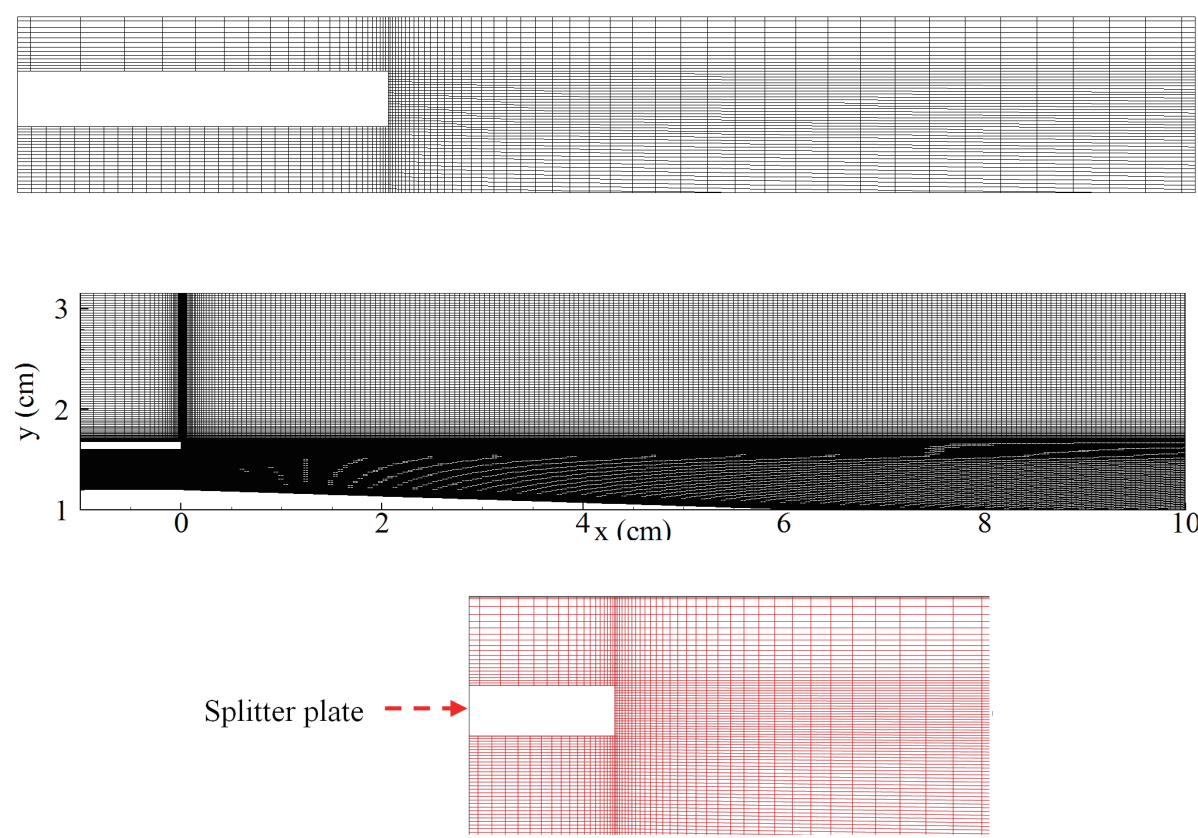

Fig. 3. Compuational grid (721 $\times 521$ for main combustor) 
time scale (shown in Fig. 4) was monitored. We note that the minimum physical time required for the solution to attain steady state is after $4 \mathrm{~ms}$, regardless of the grid resolution. In this study, the time-averaged results were taken after $8 \mathrm{~ms}$ by monitoring the regular changes in the pressure history plot (Fig. 4).

\subsection{Mesh Refinement Study}

In capturing the fine scale turbulent eddies, mesh refinement plays a major role in forecasting the order of accuracy. Norris and Edwards [28] explained the importance of grid refinement in estimating the quality of the obtained solution. For the present case, grid convergence was checked for the grid sizes as described in Table 2. The fine scale turbulence can be effectively captured by a grid size of $1001 \times 521$, thus accounting for the accuracy. Figure 5 shows the static temperature contours for different grid sizes. The gradually increasing turbulent eddy capturing capability from grid sizes $181 \times 131$ to $1001 \times 521$ can be clearly visualized. Mach number profiles (Fig. 6) measured at the exit $(35.6 \mathrm{~cm})$ indicates an order of accuracy that closely matches the experimental data, depending on the grid resolution. The minimum grid size necessary to obtain the approximate profile is $541 \times 391$ (the mixing zone). The maximum Mach number attained in the experiment is 2.2. Theoretically, the obtained the maximum Mach number is 2.46 without considering side wall boundary layer effects. On resolving the boundary layer side wall effects, the resolved new Mach number is given by

$$
M(y)^{\text {New }}=\frac{M(y)_{i, j}}{M(y)_{\text {Max (numerical })}} \times M(y)_{\text {Max (experimental })}
$$

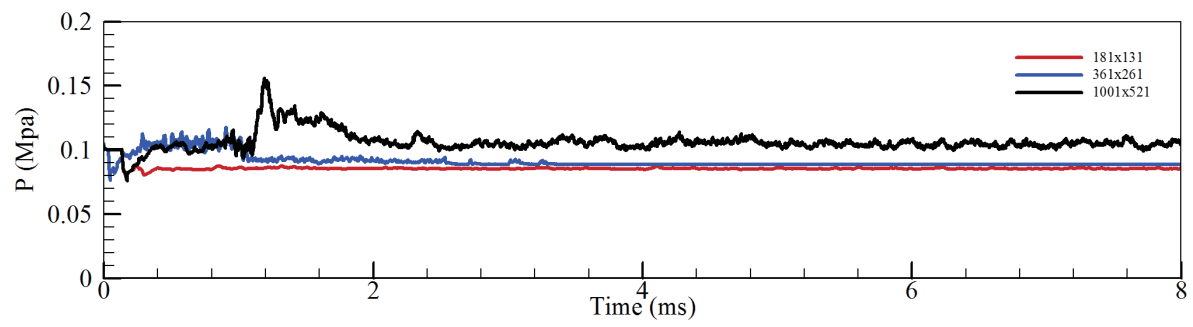

Fig. 4. Pressure history
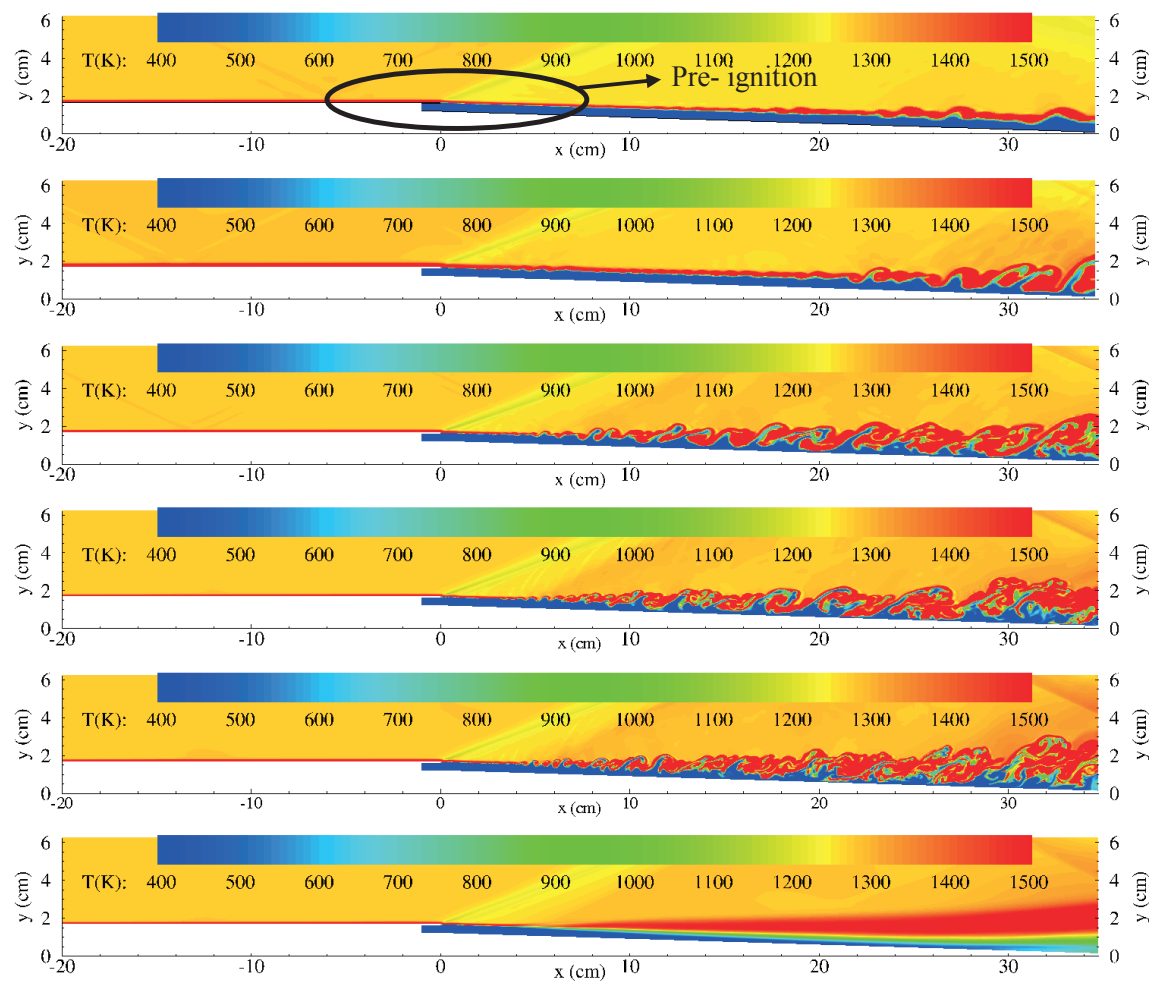

Fig. 5. Instataneous static temperature contours for grid cases (1-5) and time-averaged contour for grid size $1001 \times 521$ 


\subsection{Reactive Flow Physics Features}

The DES model is capable of capturing the shock wave emerging from the injector tip and the shock at the flame stabilization location (Fig. 5). Information regarding the shock wave was not reported in the Burrows and Kurkov experimental calculation. The flame was stabilized from 5 to $10 \mathrm{~cm}$ upstream of the combustor, where the second shock wave emerged. However, the shock wave was not strong enough to account for any effects in the flow physics.

The adiabatic wall temperature imposed at wall boundaries resulted in pre-ignition phenomena upstream of the mixing zone as shown in Figs. 5 and 7. This is due to the boundary layer temperature profile $(2000 \mathrm{~K})$, which

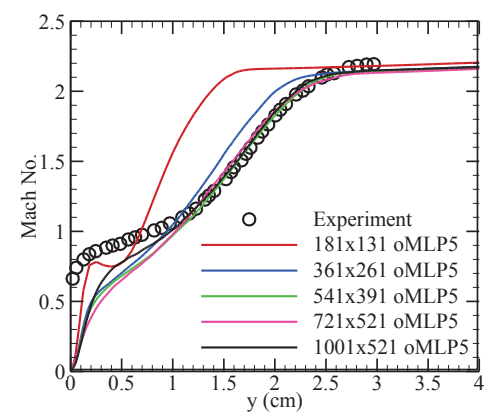

Fig. 6. Time averaged mach number profiles for different grid system was high enough to react with hydrogen. Thus, the current solution with the hot wall moved the flame front almost 10 cm upstream, but the Burrows and Kurkov experimental data of the flame front location is shown around $18 \mathrm{~cm}$. Only slight ignition is noticed at the beginning because only small quantities of hydrogen and air are mixed at the combustor entrance.

\subsection{Analysis of Preliminary Results}

The static temperature, species mole fractions, pitot and wall pressure graphs were validated with respect to the experimental conditions. Figure 8 shows the time-averaged static and stagnation temperature profiles at the exit of the combustor. The maximum static temperature attained in the present configuration is $1600 \mathrm{~K}$ for the smallest grid resolution of $181 \times 131$. This static temperature is very low when compared with the experimental temperature profiles. Finally, to identify the reactivity computed by the code, the mole fractions at the combustor exit $(\mathrm{x}=35.6 \mathrm{~cm})$ are shown in Fig. 9 for grid sizes $541 \times 391,721 \times 521$, and $1001 \times 521$. The peak in mole fraction of the water concentration is not observed, as shown in the experimental data. Similarly, the pitot pressure profile in Fig. 10 exhibits a discrepancy with the experimental value. On closer examination of the temperature and pressure profiles, we note that the outer
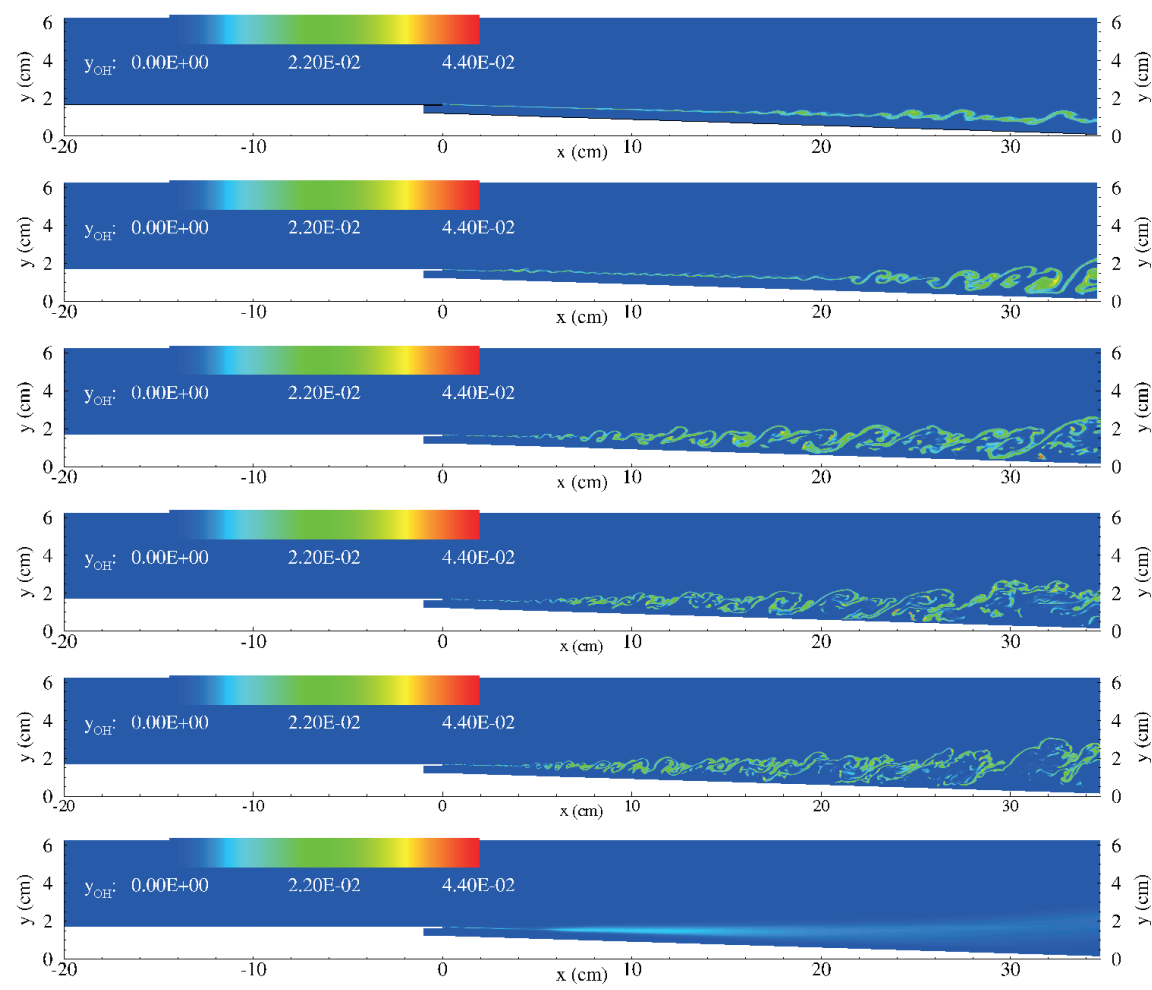

Fig. 7. Instataneous water mass fraction contours for grid cases (1-5) and time-averaged contour for grid size $1001 \times 521$ 
portion of the reactive shear layer is in good agreement with the experimental data, although the discrepancy is greater in the inner region of the shear layer.

The static temperature in the shear layer (see instantaneous image shown in Fig. 5) encountered a peak value of $2500 \mathrm{~K}$ when compared to the time-averaged static temperature. The same effect was addressed by Edwards et al. [17]. They explained the effect due to the straining of diffusive flames when large-eddies interact within the reactive flow streams. This occurs because the large eddies that interact with the reactant streams locally strain the flame and cools it through the engulfment of colder pockets of fluid in which the energy is focused on large scales. Therefore, the reason behind the discrepancy with the experimental results must be identified in order to achieve the expected results. A number of improvements need to be made in order to validate the experimental data. Further testing is required in the following fields:

1. Turbulence-chemistry interaction.

2. Chemical kinetics.

3. Improvement of numerical turbulence model.

\subsection{Turbulence-Chemistry Interaction}

An understanding of the turbulent chemistry interaction

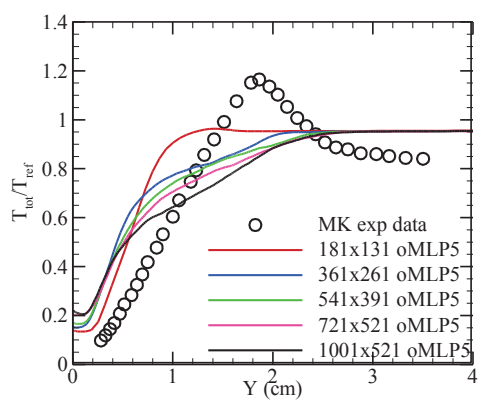

is important in identifying the physics of the reactive flows. By analyzing significant parameters including the mixture fraction, scalar dissipation rate, and flame index, the structure of the diffusive flames can be analyzed.

Computing the mixture fraction enables to track the mixing of all the elements in a chemical reaction, because the elements are unchanged during chemical process. The maximum and the minimum value for the mixture fraction are 0 for the oxidizer zone and 1 for the fuel zone. The mixture fraction definition is based on a hydrogen element that is calculated using the following formula

$$
f=y_{H}+y_{H_{2}}+y_{H_{2} \mathrm{O}} \frac{M w_{H_{2}}}{M w_{H_{2} \mathrm{O}}}+y_{\mathrm{OH}} \frac{M w_{H}}{M w_{\mathrm{OH}}}
$$

Figure 11 represents the species mass fraction versus mixture fraction calculated at locations $\mathrm{x}=0,9.95,22.6$, and $35.6 \mathrm{~cm}$ on the combustor. It is evident that at the inlet, the hydrogen and oxygen mass concentrations deplete to form few water molecules (green), indicating the pre-ignition. At the exit, the reaction has proceeded by producing water; however, the time-averaged water production does not correlate well with the experimental data since the hydrogen burnt is less than $40 \%$ in the current model. A similar trend is noted in Fig. 12, which shows scatter plots of water and

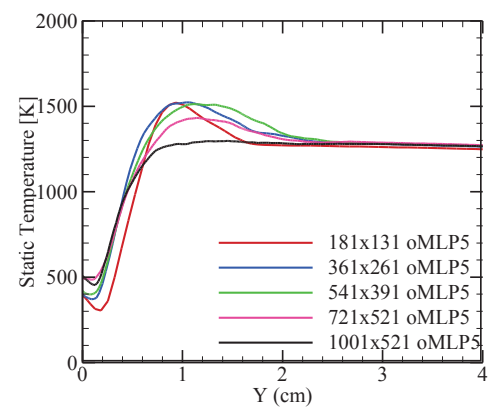

Fig. 8. Time-averaged static and stagnation temperature profiles (at combustor exit)

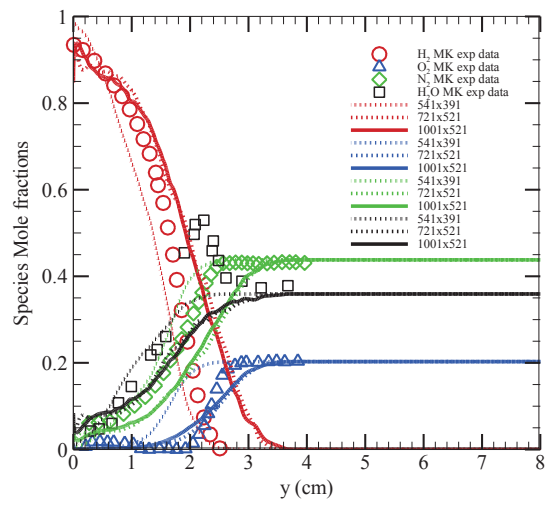

Fig. 9. Mole fraction profiles at the combustor exit

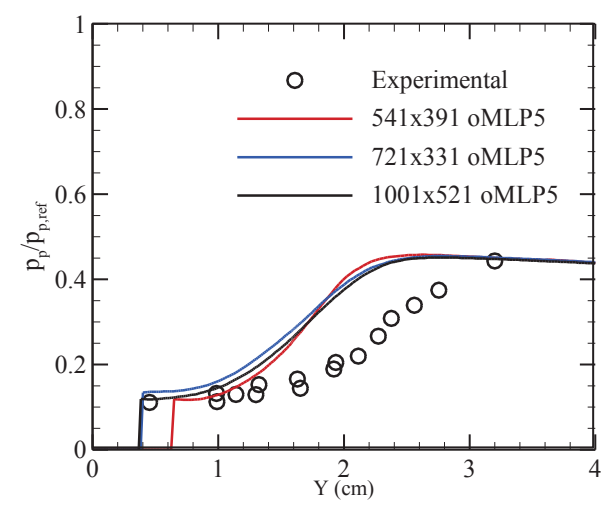

Fig. 10. Pitot pressure distribution at the exit 
oxygen mass fraction and mixture fraction varying by temperature on a 2-D x-y plane for a 1001 x 521 grid size. We suggest that the water mass fraction produced is not sufficient to account for the temperature rise leading to the disagreement with the experimental data.

We also analyzed the scalar dissipation rate (SDR) and flame index (FI), which are useful in understanding the turbulent flame structure and are given by

$$
\begin{aligned}
& \chi=2 D(\nabla f)^{2} \\
& F . I=\nabla y_{f}+\nabla y_{\alpha x}=\nabla y_{H_{2}}+\nabla y_{O_{2}}
\end{aligned}
$$

The mixing rate is characterized by the scalar dissipation rate, and is related to the straining of flame. It is well known that a higher SDR results in flame quenching. The SDR is shown in Fig. 13 for various locations $(x=9.95,20,22.6$, and $35.6 \mathrm{~cm}$ ). Initially, the SDR has the highest value of 14 , thereby indicating the thin flame structure at the upstream of the combustor. As the shear layer grows, the SDR decreases, showing the thick reaction zone in the middle of the combustor. Surprisingly, the SDR again reaches the highest value close to the wall at the combustor exit $\mathrm{x}=35.6$, indicating straining of the flame.

The FI graph with a positive value shows the premixed flame, while the negative value shows the diffusive flame. The FI plotted in Fig. 13 indicates that the combustion is mostly held in premixed condition rather than the diffusive (non-premixed) condition. The entire flame exhibits turbulent lifted flame drifting away from the lower wall of
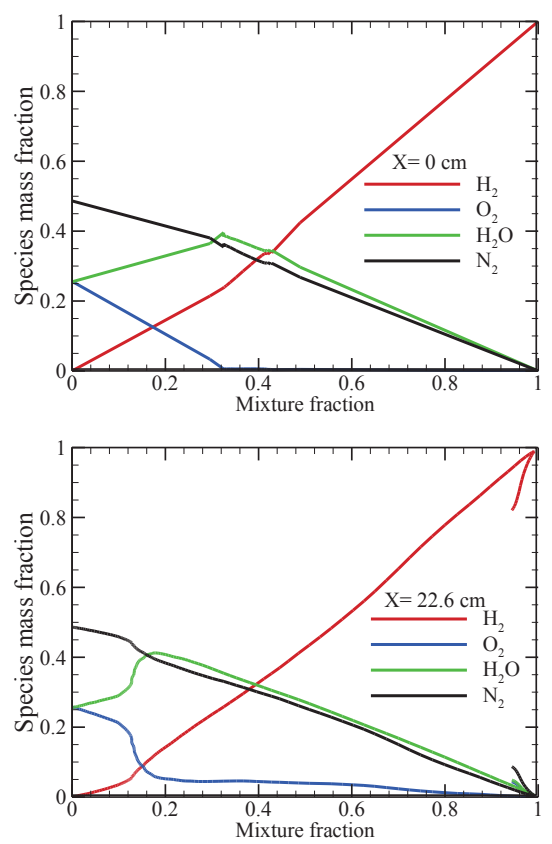

the combustor, indicating the unburned fuel and oxygen beneath and above the reaction zone.

\subsection{Implications}

Another important consideration is the three-dimensional (3-D) effect in turbulent flame/flow structures that alters the flow properties and causes discrepancies with the results of the 2-D simulation. This occurs because the side and the top wall boundary layer growth are unknown in 2-D.

An improvement is required in order to predict the accurate time-averaged properties of the reaction zone. The current numerical model under-predicts the peak in the static temperature and water concentration that implies incomplete combustion. As shown in many of the cited studies, simple RANS model predictions are generally in good agreement with the experimental data, whereas hybrid

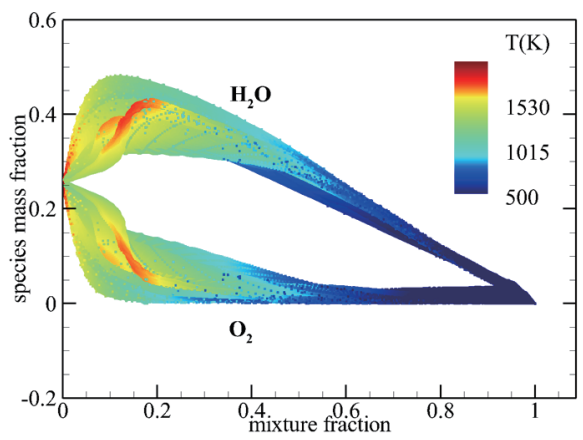

Fig. 12. Scatter plots of species mass fraction and mixture fraction varying by temperature
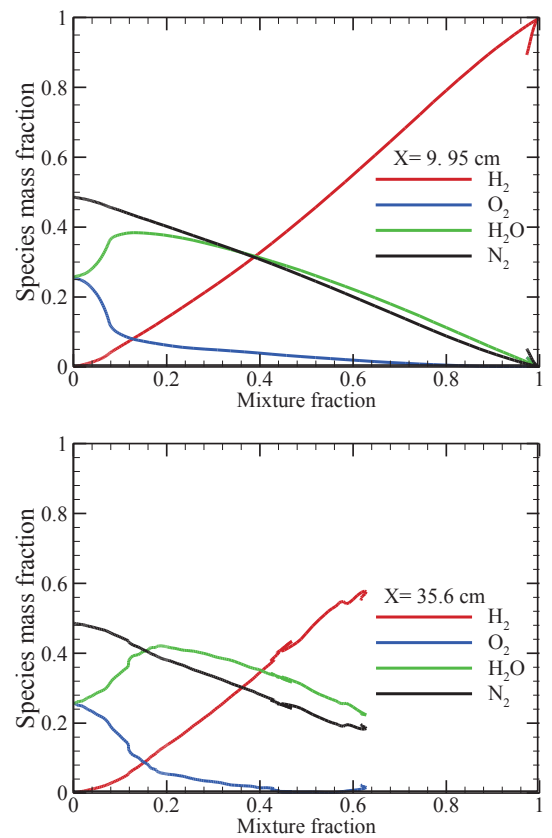

Fig. 11. Plots of species mass fraction versus mixture fraction at various locations 

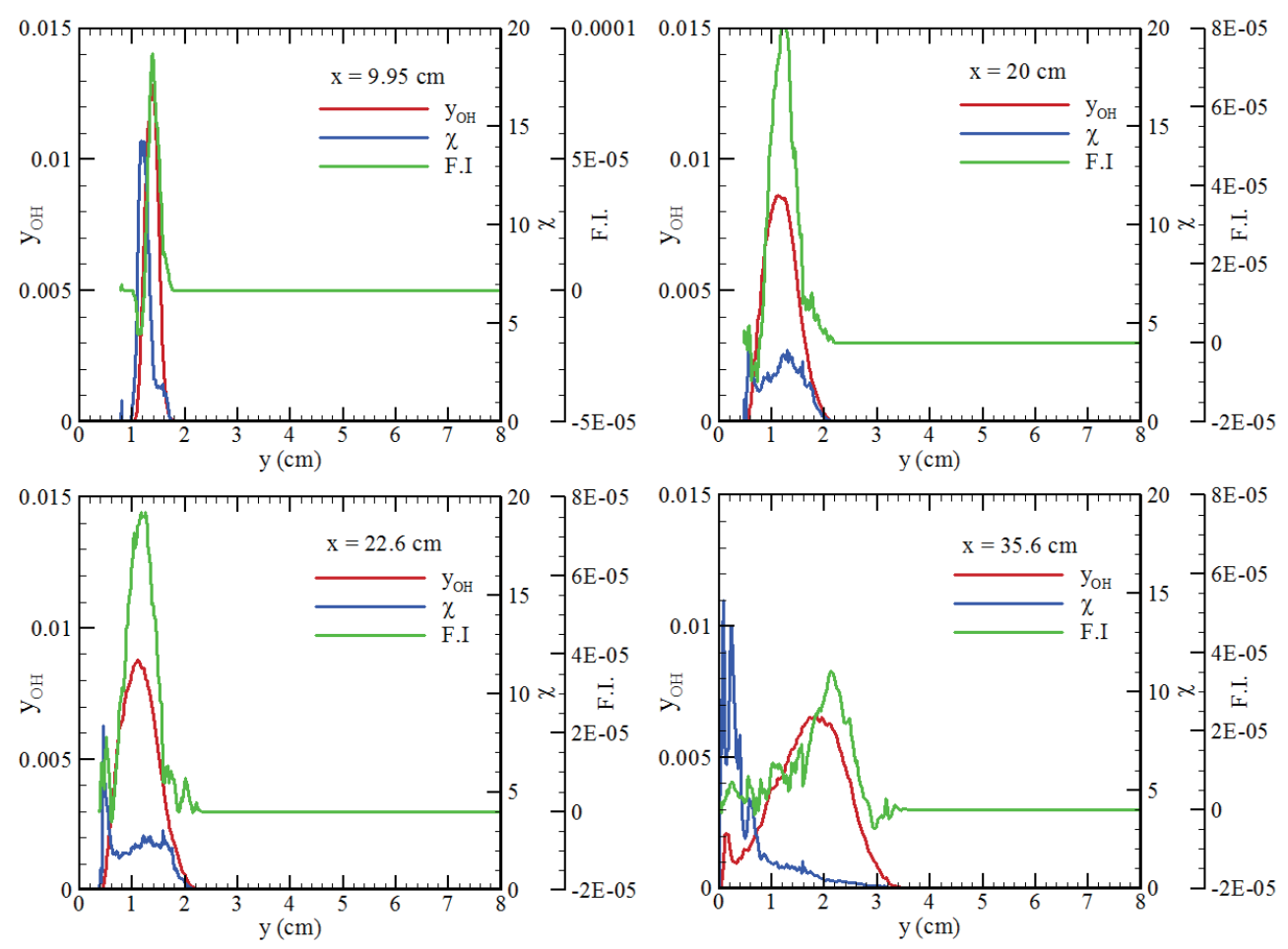

Fig. 13. Time-averaged combustion parameters at different locations for the grid $1001 \times 521$

RANS /LES predictions require improvements in order to better simulate experimental conditions. The discrepancy of under-prediction of the time-averaged temperature and water concentration is explained in Edwards et al. [31] as the effect of rapid mixing of colder reactants at larger turbulence length scales. Their study suggested the use of low diffusion models that could increase the local strain rate within a mesh cell, providing less sensitivity to fluctuating strain rates and thereby improving the time-averaged values. In the future, the use of different turbulence models, 3-D simulation, and chemical reaction mechanisms such the University of Southern California (USC) and Dryer mechanism might overcome the numerical issues suggested by Edwards et al. [31].

\section{Conclusion}

LES using DES with a fifth-order oMLP for the Burrows and Kurkov combustor model was performed. Mesh refinement studies show that a minimum grid size of 541 x 391 is required for the required solution accuracy. Preignition phenomena were noted by the use of an adiabatic wall condition. Time-averaged predictions seem to postulate some degree of disagreement with experimental data, especially in the temperature and species composition profile. Upon examination, the properties like mole fraction, total temperature and pitot pressure of the outer regions of the reaction zone are in good agreement with the experimental data whereas the discrepancy lies within the reaction zone. We assume that the reason for the dissimilarity is due to excluding the subgrid scale model, or is a result of selecting the chemical reaction mechanism of hydrogenair. On the other hand, this effect is due to rapid mixing of colder fuel engulfed at the intermittent of large scale eddies. Adequate improvement to the current numerical model is required for attaining compatibility with the experimental profiles. The analysis of turbulent chemistry interactions was useful in understanding the turbulent flame structure, but the obtained profiles were different from previous studies that simulated the same case using hybrid RANS/LES with subgrid models.

\section{Acknowledgement}

This work was supported by the Advanced Research Center Program (NRF-2013R1A5A1073861) through a National Research Foundation of Korea (NRF) grant funded by the Ministry of Science ICT and Future Planning (MSIP) 
of the Korean government, and contracted through the Advanced Space Propulsion Research Center at Seoul National University.

\section{References}

[1] Evans, J. S. and Schexnayder, C. J., "Influence of Chemical Kinetics and Unmixedness on Burning in Supersonic Hydrogen Flames," AIAA Journal, Vol. 18, No. 2, 1979, pp. 805-811.

[2] Evans, J. S. and Schexnayder, C. J., "Application of a TwoDimensional Parabolic Computer Program to Prediction of Turbulent Reacting Flows," NASA TP 1169, March 1978.

[3] Wepler, U. and Koschel, W.W., "Numerical Investigation of Turbulent Reacting Flows in a Scramjet Combustor Model," AIAA 2002-3572, Joint Propulsion Conference \& Exhibit, Jul.2002.

[4] Engblom, W. A., Frate, F. C. and Nelson, C. C., "Progress in Validation of Wind-US for Ramjet/Scramjet combustion," AIAA Aerospace Sciences Meeting and Exhibit, Jan. 2005.

[5] Xiao, X. and Hassan, A., "Modeling Scramjet Flows with Variable Turbulent Prandtl and Schmidt Numbers," AIAA Journal, Vol. 45, No. 6, Jun. 2007.

[6] Parent, B. and Sislian, J. P., "Validation Of Wilcox k- $\omega$ Model For Flows Characteristic to Hypersonic Air breathing Propulsion," AIAA journal, Vol. 42, No. 2, Feb 2004.

[7] Banaeizadeh, A., Li, Z. and Jaberi, F. A., " Large-Eddy Simulations of Compressible Turbulent Reacting Flows," AIAA Aerospace Sciences Meeting Including the New Horizons Forum and Aerospace Exposition, AIAA 2010-202, Jan.2010.

[8] Hassan, H. A., Edwards, J. R. and Fulton, J. A., "Role of Turbulence Modeling in Supersonic Combustion," AIAA Joint Propulsion Conference \& Exhibit, AIAA 2011-5829, Aug. 2011.

[9] Berglund, M. and Fureby, C., "LES of Supersonic Combustion in a Scramjet Engine Model" Proceedings of the Combustion Institute, Vol. 31, No. 2, 2007, pp. 2497-2504.

[10] Huang, W., Wang, Z-G., Li, S-B. and Liu, W-D., "Influences Of H2O Mass Fraction and Chemical Kinetics Mechanism on the Turbulent Diffusion Combustion of H2O2 in Supersonic Flows," Acta Astonautica, Vol. 76, 2012, pp. 51-59.

[11] Baurle, R. A. and Edwards, J. R., "Hybrid ReynoldsAveraged/Large-Eddy Simulations of a Coaxial Supersonic Freejet Experiment," AIAA Journal, Vol. 48, No. 3, 2010, pp. 551-571.

[12] Cutler, A. D., Diskin, G. S., Drummond, J. P. and White, J. A., "Supersonic Coaxial Jet Experiment for Computational Fluid Dynamics Code Validation," AIAA Journal, Vol. 44, No.
3, 2006, pp. 585-592.

[13] Spalart, P. R., Jou,W.-H., Strelets, M. and Allmaras, S. R., "Comments on the Feasibility of LES for Wings, and on a Hybrid RANS/LES Approach," Advances in DNS/LES: Proceedings of the First Air Force Office of Scientific Research International Conference on DNS/LES, Greyden Press, Columbus, OH, 1997, pp. 137-148.

[14] Genin, F., Chernyavsky, B. and Menon, S., "Large eddy simulation of scramjet combustion using a subgrid mixing/ combustion model," AIAA-2003-7035, Dec., 2003.

[15] Genin, F. and Menon, S., "Simulation of Turbulent Mixing Behind a Strut Injector In Supersonic Flow" AIAA Paper 2009-132, Jan. 2009.

[16] Baurle, R. A. and Edwards, J. R., "Hybrid ReynoldsAveraged/Large- Eddy Simulations of a Coaxial Supersonic Free-Jet Experiment," AIAA Paper 2009-0129, 2009.

[17] Cutler, A. D., Diskin, G. S., Drummond, J. P. and White, J. A., "Supersonic Coaxial Jet Experiment for Computational Fluid Dynamics Code Validation," AIAA Journal, Vol. 44, No. 3, 2006, pp. 585-592.

[18] Edwards, J. R, Boles, J. A. and Baurle, R. A., "LES/RANS simulation of a supersonic reacting wall jet", Combustion \& Flame, 2012.

[19] Peterson, D. M. and Candler, G. V., "Hybrid RANS/ LES of a Supersonic Combustor," AIAA Paper 2008-6923, July, 2008.

[20] Peterson, D. M., Candler, G. V., and Drayna, T. W., "Detached Eddy Simulation of a Generic Scramjet Inlet and Combustor" AIAA Paper 2009-0130, Jan. 2009.

[21] Choi, J.-Y., Yang, V. and Ma, F., "Combustion Oscillations in a Scramjet Engine Combustor with Transverse Fuel Injection," Proceedings of the Combustion Institute, Vol. 30, No. 2, 2005, time-averaged DES. pp. 2851-2858.

[22] Choi, J.-Y., Ma, F. and Yang, V., "Dynamics Combustion Characteristics in Scramjet Combustors with Transverse Fuel Injection," AIAA Paper 2005-4428, 2005.

[23] Choi, J.-Y., Han, S-.H., Kim, K.-H. and Yang, V., "High Resolution Numerical Study on the Coaxial Supersonic Turbulent Flame Structures," Propulsion and Energy Forum, AIAA 2014-3745.

[24] Choi, J.-Y., Han, S-.H., Kim, K.-H. and Yang, V., "High Resolution Numerical Study on the Supersonic Turbulent Flame Structures and Dynamics in Dual Combustion Ramjet," Propulsion and Energy Forum, AIAA 2014-3744.

[25] Kim, J.-H., Yoon, Y., Jeung, I.-S., Huh, H. and Choi, J.Y., "Numerical study of mixing enhancement by shock waves in model scramjet engine," AIAA Journal, Vol. 41, 2003, pp. 1074-1080.

[26] McBride, B. J., Gordon, S. and Reno, M. A., Coefficients for Calculating Thermodynamic and Transport Properties of 
Individual Species, NASA TM-4513, 1993.

[27] Won, S.-H., Jeung, I.-S, Parent, B. and Choi, J.-Y., "Numerical Investigation of Hydrogen Transverse Jet into Supersonic Crossflow using Detached Eddy Simulation," AIAA Journal, Vol. 48, No. 6, June, 2010, pp.1047-1058.

DOI:10.2514/1.41165

[28] Marshall, C. B. and Kurkov, A. P., Analytical and Experimental Study of Supersonic Combustion of Hydrogen in a Vitiated Air Stream, NASA TM X 2828, Sept. 1973.
[29] Norris, J. W. and Edwards, J. R., "Large-Eddy Simulation of High-Speed Turbulent Diffusion Flames with Detailed Chemistry," AIAA Paper 1997-0370, 1997.

[30] Kurkov, A. P., Mixing of supersonic jets including the effects of transverse pressure gradient using difference methods, NASA TN D-6592, Dec.1971.

[31] Peters, N., Turbulent Combustion, Cambridge University Press, U.K., 2000.

[32] https://archive.org/details/nasa_techdoc_20100003412 